\title{
HOW ADOLESCENT'S FAMILY SATISFACTION AND ATTACHMENT QUALITY CORRELATE IN CASES OF DOMESTIC VIOLENCE
}

\author{
Tatiana Dobrianskyj Weber \\ University of Northampton \\ https://doi.org/10.17060/ijodaep.2017.n1.v2.927
}

Fecha de Recepción: 12 Enero 2017

Fecha de Admisión: 1 Abril 2017

\begin{abstract}
This research examined the relationships between adolescents' attachment, communication, trust and alienation with their parents and how satisfied those adolescents are with their family life with the independent variable of having or not experienced domestic violence. Data was collected using the Inventory of Parent and Peer Attachment - Revised (IPPA - R) and the Kansas Family Life Satisfaction Scale (KFLS) and 131 adolescents participated. Results indicate a high correlation between attachment, family life satisfaction and domestic violence, with mothers' attachment, trust and communication ranking higher than fathers'. Father communication and mother trust predict family life satisfaction and exposure to domestic violence had a direct effect on family satisfaction. Cluster analysis revealed three different group. Data shows that attachment to parents remains an important aspect of family relationship and domestic violence is a phenomenon that moderates the level of family life satisfaction. Detailed findings are presented and implications and research limits are discussed.
\end{abstract}

\section{INTRODUCTION}

One of the main responsibilities of being a parent is to protect the offspring from danger and avoid or mitigate harm, especially as the children are young and unable to detect danger by themselves. Traditionally, a family is the first and main form of relationship with its protective role also serving to create and develop attachment and trust with the children, which will reflect on their relationships and choices during adulthood. But what happens when family is also the main source of fear and danger?

When interparental violence exists in a family it attacks the very meaning of its existence. Exposure to family violence can lead to emotional and mental health problems not only to the victimized parent, but on the children as well - regardless of them being a direct victim or not - and it is one of the most consistent predictors of relationship violence amongst adults (Godbout et al., 


\section{HOW ADOLESCENT'S FAMILY SATISFACTION AND ATTACHMENT QUALITY CORRELATE IN CASES OF DOMESTIC VIOLENCE}

2009), as adolescents are likely to use their parents' relationship as models to their own romantic relationship (Bandura, 1977).

Inconsistent and unstructured parenting in the context of domestic violence causes the children to develop an ambivalent attitude towards their parents, being both afraid and empathic of them (Goldblatt, 2013; Hetherington, 1979; Holden \& Ritchie, 1991). Marital conflict can make family life emotionally unpleasant, leading children's insecurity and emotional distress to become greater as the level of conflict increases (Davies \& Cummings, 1994), with early history of childhood competence with peers serving to predict adult romantic relationship (Simpson et al., 2007).

Family interaction and the development of children attachment can predict their ability to cope effectively with daily problems during their adolescent years and during adulthood (Davies \& Cummings, 1994) and predict their attachment quality as adult attachment (Allen \& Hauser, 1996; Hesse, 1999). Attachment insecurity promotes less affective coping techniques, greater emotional and behavioural problems, poor socialization abilities, anxiety, and other adjustment problems (Davies \& Cummings, 1994; Greenberg, 1999). Secure attachment can be developed under unfavourable situations when the child has efficient coping techniques at the same time it acts as an extra protection from maladaptation under risk conditions (Davies \& Cummings, 1994).

Although there is an extensive literature about the effect of domestic violence in children, very little research has actually been done with children and teenagers and their own perception about the phenomenon. Given the importance of: attachment for the development of a child's emotional health; how efficient communication can act as a protective mechanism; and how the setting of domestic violence can negatively affect a child's psychological and emotional development, this research aims to assess if how teenagers perceive the quality of attachment and communication with their parents is related to their family satisfaction, both within and outside the context of domestic violence.

Developmental psychology has shown notable interest in the way in which family interaction and educational practices can influence both the aetiology and the prevention of behavioural problems appearing in childhood and adolescence. The literature is replete with data indicating that adequate parental practices are related to the promotion of the most diverse competencies and well being of their children, and that inadequate interaction and practices can result in serious behavioural problems in the lives of children and adolescents.

Studies about domestic violence are usually faced with the initial difficulty of defining what domestic violence is and how people's experiences with it should be measured (Brandt, Ward, Dawes, \& Flisher, 2005; Guterman, Cameron \& Staller, 2000; Trickett, Durán, \& Horn, 2003). Violence is usually considered to be physical violence and psychological violence is ignored, and the domestic usually means spousal when it can also be targeted at children and other family members. The measurement of people's experiences with domestic violence is also complicated, as "exposure" can include witnessing at home or at the community or being directly victimized. The only absolute consensus concerning exposure to domestic violence is that it has a negative effect on people's life. Thus, for this research it was allowed for the participants to decide if they believe they have experienced domestic violence.

How the individual is affected by the domestic abuse is essential to understand how to intervene and maximize positive outcomes. There have been countless researches that explore the elements of domestic violence, life and family satisfaction, attachment, adolescence, the importance of family and communication that proved how important those factors are for a person's life and adjustment development. However, the relationship between all of these factors hasn't been correlated in many researches even though they are all connected. 
Adolescence is a crucial stage to examine how experiencing domestic abuse can transform into dating violence and intergenerational transmission of intimate partner violence (Collins, 2003). According to Social Learning Theory, attachment has a big part to play in this transformation, but studies so far also seem to focus more on how attachment develops at an early age or how they affect adult relationships and not how they are expressed during teenage years (Joseph et al., 2014; Gentzler et al., 2014). Research has also examined behavioural predictors of dating violence (e.g., Ehrensaft et al., 2003; Roberts et al., 2011) and failed to examine adolescent relational risk factors for dating violence to the same extent (Narayan et al., 2013). Family satisfaction allows a relatively simple and unique view on how the adolescents rate their environment and their family relationship.

Dating violence aside, understanding the development of attachment along with domestic violence can help elucidate fundamental social interactions to reduce not only conflict, but also the other damaging consequences of domestic violence and poor attachment together.

Although a thorough review and investigation on domestic violence, attachment and family satisfaction is beyond the scope of this study, given the importance and impact of all of those factors in a person's development, the current study aims to throw begin digging into the correlation of this underrated combination of factors. It is worth noting that a thorough analyses.

The aim of this study is to investigate the relationship between attachment and family life satisfaction among adolescents who have or have not suffered domestic violence.

\section{METHOD}

\section{Design:}

This research used a quantitative, correlational and descriptive approach analysed with multiple regression and cluster analysis with two self-report questionnaires comprised of closed-ended scale questions to measure the dependent variable of family attachment and family satisfaction. The independent variables were age, gender (male, female and transgender) and the previous experience of domestic violence, which was collected with a close-ended question for the participant to confirm or deny having the experience.

\section{Participants:}

A convenience sample of 131 participants took part in this study, of which $82(62.6 \%)$ were females, $41(31.3 \%)$ were males and $8(6.1 \%)$ were transsexuals. A total of 91 participants were recruited in local high schools and different youth groups with young people from various backgrounds, social economic status and experiences. An online version of the questionnaires was also created and advertised on social media, where 40 participants took part.

Participants were between 16 and 18 years of age due to ethical reasons as by 16 there is no need for parental consent and by 18 the young person is considered to be an adult. The original questionnaire was developed with samples aged 16 to 20 - although the Revised version has been successfully used with participants as young as 9 (Gullone \& Robinson, 2005).

\section{Material:}

Participants' received an Information Sheet for them to take home - it contained a brief explanation about the research, a unique participation number and the researcher's information in case they wished to withdraw. The Consent Form, where they provided their signature agreeing to participate, also contained the questions for the independent variables of age, gender and of the experience of domestic violence.

Two instruments were used to collect the dependent variables: 


\section{HOW ADOLESCENT'S FAMILY SATISFACTION AND ATTACHMENT QUALITY CORRELATE IN CASES OF DOMESTIC VIOLENCE}

Inventory of Parent and Peer Attachment - Revised (IPPA - R): The revised version of this instrument was used, which contains a total of 75 questions divided into three forms: mother attachment (25), father attachment (25) and peer attachment (however, due to the nature of this research, peer relationships weren't evaluated). This is a self report questionnaire with a five-point Likert scale response format $(1=$ Strongly disagree to $5=$ Strongly agree $)$ that measures 3 sub-scales of attachment: communication, trust and alienation. The revised version has an internal consistency (Cronbach's Alpha) of .87 for mother attachment and .89 for father attachment (Armsden \& Greenberg, 1987).

Kansas Family Life Satisfaction Scale (KFLS): This scale consists in 4 items with each item being rated on a seven-point Likert scale, from ( $1=$ Extremely dissatisfied to $7=$ Extremely satisfied). This scale was chosen because of its proven reliability, with alphas that range from 0.79 to 0.83 (Schumm, Jurich \& Bollman, 1986, apud Fischer \& Corcoran, 2000) and because this scale is significantly shorter and quicker to administer than its alternatives.

The online version consisted on the same information sheet - participants' signature weren't collected and they were informed that by answering the whole questionnaire they were automatically consenting. By the end of the online questionnaire, however, there was a Debrief page to thank them for participating and with information on where they could seek mental health assistance if they felt distressed.

\section{Procedure:}

When planning the proposed research, participants were going be contacted through social workers and organizations that work directly with mental health or victims of domestic violence, however due to data protection laws they were not able to help. Therefore, different schools, colleges and youth groups were contacted and once they granted permission the adolescents were invited to answer the questionnaires. Participants were reassured prior and following completing the questionnaires that the information was confidential, they could stop answering anytime and that they could contact the researcher for enquiries or to withdraw - nobody manifested.

\section{Ethical considerations:}

The Division of Psychology Ethics Review Committee of Northampton University approved this study on the 26th June 2015. Nonetheless, domestic violence is a sensitive subject to research and gaining access to young people who have this experience was proven difficult - as described above, data protection made it impossible to access them directly through organizations and social workers. The question for domestic violence was made very simple and factual rather than exploratory to decrease the risk of participants feeling distressed and augmenting the probability that they would be willing to answer.

In general, all of the teenagers that were aged between 16 and 18 were keen in participating regardless of their personal experience; nobody showed or reported any feeling of distress and most participants showed excitement in having their voices heard. Group leaders and teachers also showed interest and some of them reported appreciation for the research and agreed that domestic violence is a problem for teenagers and it needs investigating.

\section{RESULTS}

Table 1 shows the answers regarding gender given by the adolescents who agreed to take part in the study. Table 2 shows that $30.53 \%$ of the adolescents stated having experienced some kind of domestic violence in their family. There is no statistically significant difference with regard to gender and exposure to domestic violence $(\chi 2=1.35, d f=2, p=0.509)$. 
Table 1:

Gender frequency and percentage of the study participants

\begin{tabular}{ccc}
\hline Gender & $\mathrm{n}$ & $\%$ \\
\hline Female & 82 & $62.6 \%$ \\
Male & 41 & $31.3 \%$ \\
Female transexual & 1 & $0.8 \%$ \\
Male transexual & 5 & $3.8 \%$ \\
Transexual & 2 & $1.5 \%$ \\
\hline Total & 131 & $100 \%$ \\
\hline
\end{tabular}

Table 2:

Frequency and percentage of total participants divided into those who have experienced

\begin{tabular}{ccc}
\hline Group & N & $\%$ \\
\hline No Domestic Violence (No DV) & 91 & $69.47 \%$ \\
Domestic violence (DV) & 40 & $30.53 \%$ \\
\hline Total & 131 & $100 \%$ \\
\hline
\end{tabular}

Table 3 shows the difference between the mean scores of the scales investigated in relation to the adolescents' Mothers and Fathers. Based on the $t$ test for paired samples, fathers' means are lower than mothers' for Trust, Communication and Attachment, whilst they are higher for Alienation $(p<0.01)$. This means that the majority of the adolescents perceive greater trust, communication and attachment to their mothers, and more alienation towards the father figure.

Table 3:

Student's t test comparison of the adolescents' perception as to different variables measured regarding Mothers' and Fathers' behaviour

\begin{tabular}{cccccccc}
\hline \multirow{2}{*}{ Variables measured } & Mean & $\mathrm{N}$ & $\begin{array}{c}\text { Std. } \\
\text { Deviation }\end{array}$ & $\begin{array}{c}\text { Std. Error } \\
\text { Mean }\end{array}$ & $\mathrm{t}$ & $\mathrm{df}$ & $\begin{array}{c}\text { Sig. (2- } \\
\text { tailed) }\end{array}$ \\
\hline Mother Trust & 3.9423 & 123 & .77777 & .07013 & 4.655 & 122 & $.000 * *$ \\
Father Trust & 3.5041 & 123 & .95509 & .08612 & & & \\
$\quad$ Mother & 3.5310 & 123 & .91546 & .08254 & 6.217 & 122 & $.000 * *$ \\
Communication & & & & & & & \\
Father Communication & 2.9415 & 123 & .93801 & .08458 & & & \\
Mother Alienation & 2.6070 & 123 & .84826 & .07649 & -4.033 & 122 & $.000 * *$ \\
Father Alienation & 2.9241 & 123 & .94721 & .08541 & & & \\
Mother Attachment & 3.6636 & 117 & .79320 & .07333 & 5.544 & 116 & $.000 * *$ \\
Father Attachment & 3.1737 & 117 & .88163 & .08151 & & & \\
\hline \multicolumn{7}{c}{$* * \mathrm{p}<0.01$}
\end{tabular}

It is interesting to note in Table 4 that the fact of being transsexual is not related to exposure to domestic violence. There is just a slight trend of females having reported greater exposure to this type of violence. 
Table 4:

Adolescents' replies about the occurrence of exposure to domestic violence, by gender

\begin{tabular}{cccc}
\hline No DV / DV & Female & Male & Transexual \\
No DV & $65.85 \%(54)$ & $75.61 \%(31)$ & $75.00 \%(6)$ \\
DV & $34.15 \%(28)$ & $24.39 \%(10)$ & $25.00 \%(2)$ \\
\hline Total & $100 \%(82)$ & $100 \%(41)$ & $100 \%(8)$ \\
\hline & & $\left(\chi^{2}=1.35, \mathrm{df}=2, \mathrm{p}=0.509\right)$
\end{tabular}

Through the ANOVA-Tukey test, mother and father trust and mother communication was lower for transsexual participants than for the other males or females (Table 5). The same relation was found for mother and father attachment and an inverse relation was found for mother and father alienation. There are no significant differences for family life satisfaction and father communication between male, female and transsexual adolescents.

The participants' age had no correlation with the variables investigated $(r=0.006 ; p=0.946)$ and, which was expected as participants' age was very similar.

Table 5:

ANOVA - Tuckey test linking transsexual adolescent scores with regard to their fathers and mothers

\begin{tabular}{|c|c|c|c|c|c|c|}
\hline Variables measured & & $\begin{array}{l}\text { Sum of } \\
\text { Squares }\end{array}$ & $\mathrm{df}$ & $\begin{array}{l}\text { Mean } \\
\text { Square }\end{array}$ & $\mathrm{F}$ & Sig. \\
\hline Mother Trust & Total & 77.565 & 129 & 2.585 & 4.535 & $.013 *$ \\
\hline Father Trust & $\begin{array}{c}\text { Between } \\
\text { Groups }\end{array}$ & 111.297 & 123 & 3.060 & 3.521 & $.033 *$ \\
\hline Mother Communication & Total & 105.718 & 129 & 2.447 & 3.082 & $.049 *$ \\
\hline Father Communication & Total & 107.346 & 123 & 2.001 & 2.343 & .100 \\
\hline Mother Alienation & Total & 89.514 & 129 & 2.698 & 4.073 & $.019 *$ \\
\hline Father Alienation & Total & 110.028 & 123 & 3.527 & 4.144 & $.018 *$ \\
\hline Mother Attachment & Total & 75.709 & 123 & 2.596 & 4.455 & $.014 *$ \\
\hline Father Attachment & Total & 90.234 & 117 & 2.520 & 3.401 & $.037 *$ \\
\hline Family Life Satisfaction & Total & 190.101 & 130 & 2.556 & 1.769 & .175 \\
\hline
\end{tabular}

Table 6 shows the analysis of the variables investigated with the exposure to domestic violence; $t$ Test for independent samples indicates lower means for Attachment and Family Life Satisfaction in families exposed to domestic violence. 
Table 6:

Mean, standard deviation and $t$ Test relating the perceived trust, communication, alienation and attachment variables regarding mothers and fathers of adolescents who had or had not experienced domestic violence in their family

\begin{tabular}{ccccccccc}
\hline Family variables & $\begin{array}{c}\text { Domestic } \\
\text { Violence }\end{array}$ & N & Mean & $\begin{array}{c}\text { Std. } \\
\text { Deviation }\end{array}$ & $\begin{array}{c}\text { Etr. } \\
\text { Mean }\end{array}$ & t & df & $\begin{array}{c}\text { Sig. (2- } \\
\text { tailed) }\end{array}$ \\
\hline Mother Trust & No DV & 90 & 4.12 & .58 & .06 & 3.26 & 51.08 & $.002^{*}$ \\
& DV & 40 & 3.57 & 1.00 & .16 & & & \\
Father Trust & No DV & 85 & 3.73 & .87 & .09 & 4.20 & 122.00 & $.000^{*}$ \\
& DV & 39 & 3.01 & .94 & .15 & & & \\
Mother & No DV & 90 & 3.70 & .76 & .08 & 2.47 & 56.34 & $.016^{*}$ \\
Communication & DV & 40 & 3.22 & 1.10 & .17 & & & \\
Father & No DV & 85 & 3.20 & .86 & .09 & 4.93 & 122.00 & $.000^{*}$ \\
Communication & DV & 39 & 2.38 & .84 & .14 & & & \\
Mother & No DV & 90 & 2.36 & .72 & .08 & -5.11 & 128.00 & $.000^{*}$ \\
Alienation & DV & 40 & 3.10 & .85 & .13 & & & \\
Father & No DV & 85 & 2.61 & .89 & .10 & -5.99 & 122.00 & $.000^{*}$ \\
Alienation & DV & 39 & 3.58 & .70 & .11 & & & \\
Family Life & No DV & 91 & 5.22 & 1.16 & .12 & 5.68 & 129.00 & $.000^{*}$ \\
Satisfaction & DV & 40 & 4.05 & .90 & .14 & & & \\
Mother & No DV & 85 & 3.86 & .61 & .07 & 3.44 & 52.46 & $.001^{*}$ \\
Attachment & DV & 39 & 3.28 & .97 & .15 & & & \\
Father & No DV & 80 & 3.44 & .80 & .09 & 5.20 & 116.00 & $.000^{*}$ \\
Attachment & DV & 38 & 2.62 & .78 & .13 & & & \\
\hline & & & $*$ & 0.05 & & & &
\end{tabular}

Table 7:

shows a clear correlation between family variables and Family Life Satisfaction, whereby Mother Trust and Mother Attachment are the strongest.

\begin{tabular}{lccc}
\hline & \multicolumn{3}{c}{ Family Life Satisfaction (DV } \\
group)
\end{tabular}




\section{HOW ADOLESCENT'S FAMILY SATISFACTION AND ATTACHMENT QUALITY CORRELATE IN CASES OF DOMESTIC VIOLENCE}

Table 8 shows a clear relationship between the Life Satisfaction (categorized) scale and exposure to Domestic Violence. There is a clear statistically significant and inverse relationship between Life Satisfaction and exposure or non-exposure to domestic violence. Extreme opposites can be seen, in that $55 \%$ of those exposed to domestic violence have low Family Life Satisfaction, whilst $37.36 \%$ of those not exposed to domestic violence have high Life Satisfaction.

Table 8:

Cross-referencing of data provided by adolescents on the categorized Life Satisfaction scale with DV and No DV

\begin{tabular}{ccc}
\hline $\begin{array}{c}\text { Life Satisfaction } \\
\text { categorized }\end{array}$ & \multicolumn{2}{c}{ Domestic violence } \\
\hline Low & No DV & DV \\
& 18 & 22 \\
Median & $19.78 \%$ & $55.00 \%$ \\
& 39 & 16 \\
High & $42.86 \%$ & $40.00 \%$ \\
& 34 & 2 \\
Total & $37.36 \%$ & $5.00 \%$ \\
& 91 & 40 \\
& $100 \%$ & $100 \%$ \\
\hline & $\left(\chi^{2}=21.93, \mathrm{df}=2, \mathrm{p}<0.001\right)$
\end{tabular}

Two further cross-referenced Tables (9 and 10) show the inverse relationship between mother and father Alienation and domestic violence. Exposure to domestic violence is more present in environments with mother and father alienation. Father alienation appears to be more strongly associated with domestic violence.

Table 9:

Cross-referencing of data provided by adolescents on the categorized Mother Alienation scale with DV and No DV

\begin{tabular}{ccc}
\hline $\begin{array}{c}\text { Mother } \\
\text { alienation }\end{array}$ & \multicolumn{2}{c}{ Domestic violence } \\
\hline \multirow{2}{*}{ Low } & No DV & DV \\
& 33 & 4 \\
Median & $36.37 \%$ & $10.00 \%$ \\
& 47 & 19 \\
High & $52.22 \%$ & $47.50 \%$ \\
& 10 & 17 \\
Total & $11.11 \%$ & $42.50 \%$ \\
& 90 & 40 \\
& $100 \%$ & $100 \%$ \\
\hline & $\left(\chi^{2}=20.177, \mathrm{df}=2, \mathrm{p}<0.001\right)$
\end{tabular}


Table 10:

Cross-referencing of data provided by adolescents on the categorized

Father Alienation scale with DV and No DV

\begin{tabular}{ccc}
\hline $\begin{array}{c}\text { Father } \\
\text { alienation }\end{array}$ & \multicolumn{2}{c}{ Domestic violence } \\
\hline \multirow{3}{*}{ Low } & No DV & DV \\
& 33 & 1 \\
Median & $38.82 \%$ & $2.56 \%$ \\
& 40 & 21 \\
High & $47.06 \%$ & $53.85 \%$ \\
& 12 & 17 \\
Total & $14.12 \%$ & $43.59 \%$ \\
& 85 & 39 \\
& $100 \%$ & $100 \%$ \\
\hline & $\left(\chi^{2}=20.177, \mathrm{df}=2, \mathrm{p}<0.001\right)$
\end{tabular}

\section{DISCUSSION}

Data shows that attachment, communication, trust, alienation and family satisfaction are all correlated for both mothers and fathers, thus reinforcing the original idea that they all influence each other. The higher the quality of attachment (and, automatically, communication and trust) the higher was the quality of family life satisfaction whilst alienation was low.

Based on the $t$ test for paired samples, fathers' means are lower in the total of attachment and its' sub-scales. Through Pearson Correlation, all three dimensions and general measure of attachment are related to Family Life Satisfaction, either for mother and father attachment. Linear regression shows that Maternal and paternal attachment in $49.5 \%(R 2)$, where family satisfaction $=0.754$ +0.496 , mother attachment +0.719 and father attachment $(F=55.79, p<0.001)$. Specifically, father communication and mother trust explained family life satisfaction in $45.3 \%$ (R2), with family life satisfaction $=0.881+0.602$, father communication +0.559 and mother trust $(F=49.60, p<0.001)$.

Curiously, there was no significant difference between genders male and female, with all genders having the same likelihood of experiencing domestic violence and evaluating their parents similarly. Literature claims that there usually are differences on how males and females experience the consequences of domestic violence, with girls being more prone to internalizing and externalizing problem due to negative maternal practices and boys expressing more aggressiveness and anxiety due to paternal rejection (Roelofs et al., 2006). Thus, it was expected that males and females would have a better relationship with one of the parents, but this was not found.

There was interesting data about the transsexuals as they reported less trust and greater alienation to their father when compared to male and females, whose results were practically equal. However, due to the small sample of transsexuals in the samples, this result is only a trend that should be better explored in future researches.

Although younger children are more at risk of being a victim of domestic violence as they are more dependant on their parents, participant's age also had no correlation with the variables, which was expected considering the ages did not vary too much. Therefore, exposure to Domestic Violence does not depend on the adolescent's age or gender, but rather on family interactions.

As expected, adolescents who haven't experienced Domestic Violence were significantly more satisfied with their family life than the ones who have; $t$ test for independent samples indicates lowers means of attachment and satisfaction in families exposed to domestic violence. 


\section{HOW ADOLESCENT'S FAMILY SATISFACTION AND ATTACHMENT QUALITY CORRELATE IN CASES OF DOMESTIC VIOLENCE}

Means of attachment, communication and trust were higher for individuals with no Domestic Violence than with Domestic Violence in poorer attachment to parents (Sousa et al., 2011). It is still possible for adolescents exposed to DV to form secure attachment with their parent through efficient communication and trust, which enhances the chance of family satisfaction (Sternberg et al., 1994; Lamb et al., 1985; Bolen, 2005).

Linear regression analysis showed that DV has a direct effect on family satisfaction, $R^{2}=.22$, $F(1,115)=32.77, p<.001$. The prediction was stronger when considering mother and father's attachment, $R^{2}=.51, F(3,113)=39.04, p<.001$, although father's attachment was stronger $(\beta=.47)$ than the mother $(\beta=.21)$ and than DV $(\beta=-.17)$.

Findings from this study reveal the impact of Domestic Violence and the complexity of family systems and should be further investigated.

\section{REFERENCES}

Bandura, A. (1977). Social learning theory. Englewood Cliffs, NJ: Prentice Hall.

Bolen, R. M. (2005). Attachment and family violence: complexities in knowing. Child Abuse \& Neglect, 29(8), 845-852.

Collins, W. A. (2003). More than a myth: The developmental significance of romantic relationships during adolescence. Journal of Research on Adolescence, 13, 1-24.

Davies, P. T., \& Cummings, E. M. (1994). Marital conflict and child adjustment: an emotional security hypothesis. Psychological Bulletin, 116, 387-411.

Ehrensaft, M. K., Cohen, P., Brown, J., Smailes, E., Chen, H., \& Johnson, J. G. (2003). Intergenerational transmission of partner violence: A 20-year prospective study. Journal of Consulting and Clinical Psychology, 71(4), 741-753.

Gentzler, A. L., Ramsey, M. A., Yi, C., Palmer, C., \& Morey, J. (2014). Young adolescents' emotional and regulatory responses to positive life events: Investigating temperament, attachment, and event characteristics. The Journal of Positive Psychology, 9(2), 108-121.

Godbout, N., Dutton, D. G., Lussier, Y., \& Sabourin, S. (2009). Early exposure to violence, domestic violence, attachment representations, and marital adjustment. Personal Relationships, 16(3),365-384.

Greenberg, M. T. (1999). Attachment and psychopathology in childhood. In J. Cassidy \& P. R. Shaver (Eds.), Handbook of attachment: Theory, research, and clinical applications. (pp. 469-496). New York: Guilford Press.

Gullone, E., \& Robinson, K. (2005). The Inventory of Parent and Peer Attachment-Revised (IPPAR) for children: a psychometric investigation. Clinical Psychology \& Psychotherapy, 12(1), 6779.

Guterman, N.B., Cameron, M., \& Staller, K. (2000). Definitional and measurement issues in the study of community violence among children and youths. Journal of Community Psychology, 28(6), 571-587.

Hetherington, E. M. (1979). Divorce. A child's perspective. American Psychologist, 34(10), 851-858.

Holden, G. W. , \& Richie, K. L. (1991). Linking extreme marital discord, child rearing and child behavior problems: Evidence from battered women. Child Development, 62, 311-327

Joseph, M. A., O'Connor, T. G., Briskman, J. A., Maughan, B., \& Scott, S. (2014). The formation of secure new attachments by children who were maltreated: An observational study of adolescents in foster care. Development and Psychopathology, 26(01), 67-80.

Lamb, M. E., Pleck, J. H., Charnov, E. L., \& Levine, J. A. (1985). Paternal behavior in humans. American Zoologist, 25(3), 883-894. 
Narayan, A. J., Englund, M. M., Carlson, E. A., \& Egeland, B. (2014). Adolescent Conflict as a Developmental Process in the Prospective Pathway from Exposure to Interparental Violence to Dating Violence. Journal of Abnormal Child Psychology, 42, 239-250.

Roberts, A. L., McLaughlin, K. A., Conron, K. J., \& Koenen, K. C. (2011). Adulthood stressors, history of childhood adversity, and risk of per- petration of intimate partner violence. American Journal of Preventative Medicine, 40, 128-138.

Roelofs, J., Meesters, C., ter Huurne, M., Bamelis, L., \& Muris, P. (2006). On the links between attachment style, parental rearing behaviors, and internalizing and externalizing problems in non-clinical children. Journal of Child and Family Studies, 15(3),319-332.

Simpson, J. A., Winterheld, H. A., Rholes, W. S., \& Oriña, M. M. (2007). Working models of attachment and reactions to different forms of caregiving from romantic partners. Journal of Personality and Social Psychology, 93, 466-477.

Souza, C., Harrenkohl, T.I., Moylan, C.A., Tajima, E.A., Klika, J.B., Herrenkohl, R.C., \& Russo, M.J. (2011). Longitudinal Study on the Effects of Child Abuse and Children's Exposure to Domestic Violence, Parent-Child Attachments, and Antisocial Behavior in Adolescence. Journal of Interpersonal Violence, 26(1), 111-136.

Sternberg, K. J., Lamb, M.E., Greenbaum, C., Dawud, S., Cortes, M., \& Lorey, F. (1994). The effects of domestic violence on children's perceptions of their perpetrating and nonperpetrating parents. International Journal of Behavioral Development, 17, 779-795.

Trickett, P.K, Duran, L., \& Horn, J.L. (2003). Community violence as it affects child development: Issues of definition. Clinical Child and Family Psychology Review, 6, 223-236.

1 This article is part of a thesis submitted to The University of Northampton (UK) for the degree of MSc Child and Adolescent Mental Health. 
